\title{
AUTOREGULATION OF RENAL BLOOD FLOW: ALTERATION BY METHOXYFLURANE
}

\author{
K.M. Leighton, M.B., CH.B., F.R.C.P.(C), Beverly Koth, AND \\ BeverLy M. WENKSTERN *
}

THE FLOW OF BLOOD to the kidneys is apparently controlled by these organs themselves. Within certain limits this flow is independent of fluctuations in arterial pressure. ${ }^{1}$ Thus renal blood flow tends to remain relatively constant in spite of the many fluctuations in pressure to which the systemic circulation is subject.

That this regulation is indeed an autonomous function of the organ is shown by experiments involving isolated perfused kidneys wherein renal blood flow remains constant in the face of changing perfusion pressures. ${ }^{2}$

The upper and lower limits of mean arterial pressure throughout which this autoregulation is maintained are variously described. Hatch and Johnson, in their review of intrarenal blood flow published in 1969, give the figures of $200 \mathrm{~mm} \mathrm{Hg}$ and $70 \mathrm{~mm} \mathrm{Hg}$ respectively. ${ }^{3}$

The kidney is not paramount in the control of its blood flow. In severe haemorrhage, for example, with increased sympathetic nervous activity, renal flow may be appreciably reduced when mean arterial pressure remains above the lower critical level for normal autoregulation. ${ }^{4}$ A similar fall in blood flow may be observed in conditions of acute hypoxia where, once again, autoregulatory mechanisms are superseded..$^{5}$ This latter response is neurogenic in origin since there is no decrease in blood flow in the presence of hypoxia if the carotid sinus is first denervated and the depressor nerves sectioned. ${ }^{6}$

In the absence of such over-riding mechanisms, not only is renal blood flow subject to autoregulation but so also is glomerular filtration rate. ${ }^{7}$ This latter observation suggested a preglomerular site for autoregulation and this appears to have been confirmed by experimental observation. ${ }^{8}$

It should be noted that although it has generally been held that autoregulation of renal blood flow applies only to cortical perfusion ${ }^{9}$ Grangsjo and Wolgast have presented convincing evidence recently for autoregulation of medullary blood flow. ${ }^{10}$ The significance of this is obvious. Although only some seven percent of the total blood flow to the kidney perfuses medullary tissue, this flow may profoundly affect interstitial osmolarity in the vicinity of the collecting systems of the nephron and this, in turn, influences the character of the final urinary product.

Considerable debate has centred upon the mechanisms whereby the kidney ex-

* From the Departments of Anaesthesia and Pharmacology, University of British Columbia. This work was supported by a grant in aid of research awarded by the British Columbia Heart Foundation.

Presented in part at the annual meeting of the Canadian Anaesthetists' Society in Halifax, June 1972. 
ercises this control of its own blood flow. ${ }^{11-13}$ Some observers contend that a change in transmural pressure within glomerular afferent arterioles is responsible for initiating a myogenic response. Thus an increase in pressure, by increasing tangential wall tension leads to a corresponding increase in vascular tone and thus a constant flow rate is maintained. ${ }^{14}$

This myogenic response has been variously explained. It appears unlikely that a decrease in renal blood flow is a function of rising interstitial pressure, as was at one time suggested. ${ }^{11}$ Thurau and others have shown that the production of a raised interstitial pressure (by promoting an osmotic diuresis and ligating the ureter) is followed by an increase in blood flow rather than the decrease which the tissue pressure theory would postulate. ${ }^{9}$

Thurau has suggested that the juxtaglomerular apparatus, at the macula densa, is capable of sensing alterations in sodium concentration within the lumen of the ascending limb of Henle's loop. When glomerular perfusion increases and glomerular filtration rate rises, so also does sodium concentration in the ascending limb. This, according to Thurau, sets in chain a sequence of events which culminates in the local release of angiotensin II. This latter then acts specifically upon the smooth muscle of the glomerular afferent arteriole. ${ }^{15}$ Vasoconstriction and reduced glomerular filtration follow.

However, some interesting work has been carried out by Leichtweiss and Schroder. ${ }^{16}$ In their experiments the kidney was perfused with mineral oil. Autoregulation was maintained in the face of changing perfusion pressures. This would appear to constitute a serious challenge to Thurau's hypothesis.

Whatever the physiological mechanism of autoregulation, it would seem teleologically important that the kidney be capable of regulating its own blood supply in the face of changing arterial pressures, since blood pressure changes in response to alterations in posture, emotion and a myriad of other events are commonplace throughout life. By this mechanism, therefore, the kidney is permitted steady glomerular perfusion and a steady glomerular filtration rate. Thus the function of the kidney as an excretory organ and the prime regulator of body water and electrolytes may proceed uninterruptedly within the generous limits provided by these mean arterial pressures of $70 \mathrm{~mm} \mathrm{Hg}$ and $200 \mathrm{~mm} \mathrm{Hg}$.

Any alteration in the efficiency of autoregulation would appear to be significant and it would seem especially important to be aware of any changes in this process induced by drugs or disease.

It seemed of interest, therefore, to observe the effects of some general anaesthetics upon renal blood flow and autoregulation. The general anaesthetic agent, methoxyflurane is of particular interest. This drug has been incriminated as being responsible for the impairment of renal function. ${ }^{15-17} \mathrm{~A}$ syndrome of high output renal failure has followed methoxyflurane administration. ${ }^{15}$ This failure has been of variable duration and severity. ${ }^{18}$

\section{ExPERIMENTAL Method}

Six dogs were studied in thirty-eight experiments. Mongrel dogs were used in chronic preparations and so were used repeatedly.

Doppler ultrasonic flow probes were calibrated in vitro, using a perfusion pump 
co
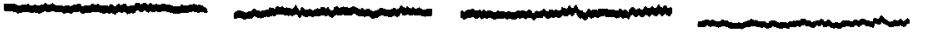

R B F

ABP
methoxyflurane
$1.5 \%$

$1.5 \%$

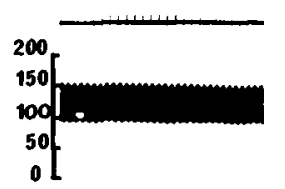

MAP $\mathrm{m} \mathrm{mm} \mathrm{Hg}$

$+55 \mathrm{~min}$

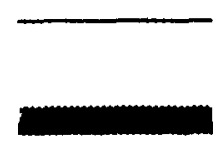

MAP $85 \mathrm{~mm} \mathrm{Hg}$

MAP $70 \mathrm{~mm} \mathrm{Hg}$

MAP $65 \mathrm{~mm} \mathrm{Hg}$

Figure 1. Prolonged methoxyflurane administration is accompanied by a fall in blood pressure and renal blood flow. Note the fall in renal blood flow when mean arterial pressure is greater than $70 \mathrm{~mm} \mathrm{Hg}$. Renal blood flow falling from $176 \mathrm{mls}$ per minute to $156 \mathrm{mls}$ per minute.

and heparinized blood. Under general anaesthesia (thiopentone, halothane and nitrous oxide) flow probes were placed around the ascending aorta and the left renal artery. Leads were brought out through the skin of the dorsum and all the wounds closed. The animals were permitted at least a week to recover from surgery.

At each experiment anaesthesia was again induced with thiopentone $(20 \mathrm{mg}$ per $\mathrm{kg}$ ) administered intravenously. Once endotracheal intubation was effected the animals were ventilated with methoxyflurane and oxygen using a Palmer pump to produce intermittent positive pressure. Methoxyflurane was vaporized in a Pentec $2^{\circledR}$. Intravenous fluid (Lactated Ringer's) was administered throughout all experiments at a rate which was reasonably constant for all animals, although the total amount of fluid obviously varied with the length of the experiment.

The femoral artery (right or left) was then cannulated to permit sampling for blood gas determinations and constant observation of arterial blood pressure. Blood gases were measured with a Radiometer BM3 analyzer calibrated with known gas mixtures. Arterial pressure was measured by employing a Statham pressure transducer $(\mathrm{P} 23 \mathrm{Dc})$. Male animals were catheterized and urine flow estimated by a simple electrical drop counter.

The temperature of the animals was maintained between $37^{\circ} \mathrm{C}$ and $38^{\circ} \mathrm{C}$ by means of a water filled warming blanket.

By altering tidal volumes, blood gas measurements were kept at $\mathrm{PaO}_{2}>100 \mathrm{~mm}$ $\mathrm{Hg}, \mathrm{PaCO}_{2} 30-40 \mathrm{~mm} \mathrm{Hg}$, and $\mathrm{pH}$ 7.36-7.45.

A Grass Polygraph (Model 7) was used to chart blood flows in the aorta and renal artery, arterial pressure and urine flow (in male dogs).

\section{Experiment Number 1 ( 3 dogs -8 experiments)}

The animal was prepared as has been described and methoxyflurane and oxygen anaesthesia maintained. Figure 1 shows that prolonged administration of methoxyflurane is accompanied by a steady fall in arterial blood pressure and in 
CO

RBF

ABP

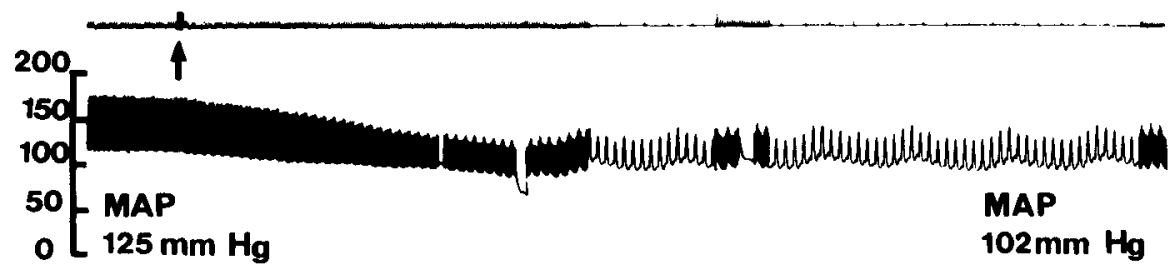

methoxyflurane increased from $1 \%$ to $2 \%$

\section{UO}

Figure 2. Under stable conditions, methoxyflurane concentration increased from 1 to 2 per cent in the inspired mixture. Mean arterial pressure stays above $100 \mathrm{~mm} \mathrm{Hg}$. Renal blood flow declines from $146 \mathrm{mls}$ per minute to $98 \mathrm{mls}$ per minute.

renal blood flow. While the former finding is not unexpected, the latter appears surprising since mean arterial blood pressure was greater than $70 \mathrm{~mm} \mathrm{Hg}$ when renal blood flow first declined. (Mean arterial blood pressure was determined by applying the formula MAP $=$ Diastolic pressure $+1 / 3$ pulse pressure.) Cardiac output can be seen to have declined at this point also. Nevertheless if autoregulation of renal blood flow were maintained, then, at a mean arterial pressure of $85 \mathrm{~mm}$ $\mathrm{Hg}$, one would not anticipate that the total renal blood flow would be diminished. Renal blood flow, in Figure 1, has fallen from $176 \mathrm{mls}$ per minute to $156 \mathrm{mls}$ per minute coincident with a fall in mean arterial pressure from $111 \mathrm{~mm} \mathrm{Hg}$ to 85 $\mathrm{mm} \mathrm{Hg}$.

\section{Experiment Number 2 ( 3 dogs - 15 experiments)}

Stable cardiac output, renal blood flow and arterial blood pressure recordings were obtained in the presence of methoxyflurane and nitrous oxide anaesthesia. The inspired concentration of methoxyflurane was increased from 1 to 2 per cent. The mean arterial pressure, which started at $125 \mathrm{~mm} \mathrm{Hg}$ fell to $102 \mathrm{~mm} \mathrm{Hg}$, cardiac output fell slightly and renal blood flow declined from $146 \mathrm{mls}$ per minute to 98 mls per minute. Once again, autoregulation of renal blood flow would appear to be impaired following methoxyflurane administration (Figure 2).

Experiment Number 3 ( 5 dogs - 15 experiments)

In this experiment observations were made on the effect upon renal blood flow of minor changes in the inspired concentration of methoxyflurane which were insufficient to produce demonstrable alterations in arterial blood pressure. Mean 
co

RBF

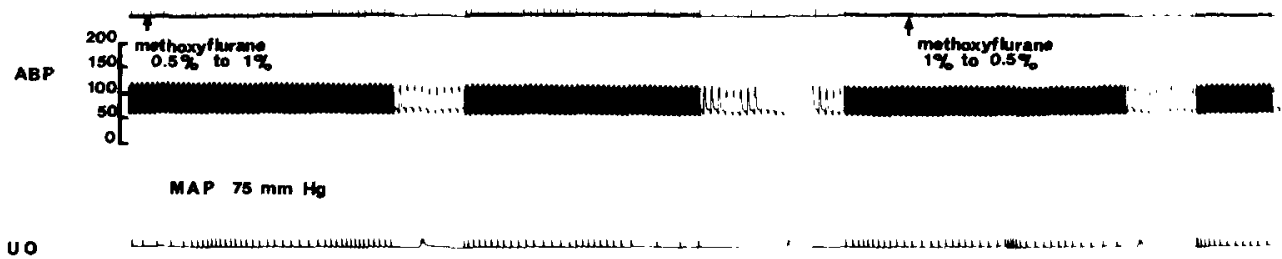

Figune 3. Under stable conditions, methoxyflurane concentration increased from 0.5 to 1 per cent in the inspired mixture. Mean arterial pressure unchanged at $75 \mathrm{~mm} \mathrm{Hg}$. Renal blood flow declines from $180 \mathrm{mls}$ per minute to $154 \mathrm{mls}$ per minute.

arterial pressure was held at $75 \mathrm{~mm} \mathrm{Hg}$ throughout. As can be seen from the illustration (Figure 3), renal blood flow fell (from $180 \mathrm{mls}$ per minute to $154 \mathrm{mls}$ per minute) when the inspired concentration of methoxyflurane was raised from 0.5 to 1.0 per cent and rose again (to $174 \mathrm{mls}$ per minute) when the concentration was reduced to 0.5 per cent once more.

\section{Discussion}

From the results of these experiments one may reasonably be entitled to draw two conclusions. Firstly, methoxyflurane appears to impair autoregulation of renal blood flow and this latter becomes pressure dependent and falls or rises, pari passu, with arterial blood pressure. Secondly, it also appears that methoxyflurane is capable of reducing renal blood flow independently of any effect which it may exert upon blood pressure.

These conclusions appear important to us inasmuch as, in the presence of methoxyflurane, a significant drop in glomerular filtration rate may follow any fall in arterial pressure (since autoregulation of renal blood flow is abolished and hence autoregulation of glomerular filtration rate is similarly impaired).

Any decrease in glomerular filtration rate must, we feel, be of significance during anaesthesia. The kidney is the ultimate route for the excretion of many drugs and the rate of tubular urine flow may influence the handling of these. In the case of molecules or ions which possess inherent nephrotoxic capabilities such as diminution in the rate of flow might presumably enhance the concentration of these molecules either within tubular urine or the interstitium of the kidney (especially, perhaps, within the renal medulla). Thurau has shown that sodium concentration in the distal tubules rises when glomerular filtration is arrested, ${ }^{9}$ and this would perhaps lend support to the possibility of intratubular concentration of toxic solutes during low flow states. The increased concentration of these toxic molecules might be productive of an enhanced toxic potential. If we consider methoxyflurane specifically in this light there is good evidence that fluoride ions possess nephrotoxic capabilities ${ }^{19}$ The syndrome is well known and critical levels of plasma 
fluoride have been established above which nephrogenic diabetes insipidus frequently develops in those patients who have received methoxyflurane anaesthesia. ${ }^{20}$

It is here contended that a possible contributory mechanism in the production of renal damage by methoxyflurane is the autoregulatory failure induced by this agent and which we have demonstrated. It is further contended that, as a consequence of the direct effect of methoxyflurane upon renal blood flow, this latter may be reduced in the absence of a fall in arterial pressure and that this may contribute to the development of the renal lesion.

Since renal blood flow may be reduced by methoxyflurane without any prior alteration in arterial pressure, this perhaps points to an effect of the agent acting directly upon the renal vasculature.

Certainly, it would seem advisable during general anaesthesia with methoxyflurane to avoid any fall in arterial pressure. Such a fall may be induced by the agent itself or by the administration of other drugs (e.g. neuromuscular blocking agents) or the employment of techniques such as hyperventilation, or by postural changes. All should perhaps be considered hazardous during methoxyflurane anaesthesia.

\section{SUMMARY}

Renal blood flow and glomerular filtration rate are autoregulated. The arterial pressure limits for this autoregulation are $200 \mathrm{~mm} \mathrm{Hg}$ and $70 \mathrm{~mm} \mathrm{Hg}$. Above and below these limits, autoregulation does not obtain. Autoregulation may also be abolished when certain stresses are applied to the organism. Such a stress is hypoxia or severe haemorrhage.

Methoxyflurane appears to modify autoregulation so that renal blood flow becomes pressure dependent. Methoxyflurane also appears to depress renal blood flow by a mechanism which is independent of pressure alterations. It is possible that both mechanisms may play a part in the development of renal damage by the products of methoxyflurane metabolism.

\section{RÉSUMÉ}

Le débit sanguin rénal et le taux de la filtration glomérulaire sont dotés d'un système autorégulateur. Les limites de la tension artérielle pour que cette autorégulation fonctionne, sont 200 et $70 \mathrm{~mm} \mathrm{Hg}$. Au delà et au-dessous de ces limites, l'autorégulation ne fonctionne plus. Cette autorégulation peut également arrêter de fonctionner si lorganisme subit certaines agressions. Une hypoxie ou une hémorragie grave peut constituer une telle agression.

Le méthoxyflurane semble capable de modifier l'autorégulation de sorte que le débit sanguin rénal devient dépendant de la pression. De plus, le méthoxyflurane semble déprimer le débit sanguin rénal par un mécanisme qui est indépendant des modifications de la pression. Il est possible que ces deux mécanismes puissent jouer un rôle dans l'apparition de dommages rénaux par les produits du métabolisme du méthoxyflurane. 


\section{REFERENCES}

1. Concoran, A.C. \& Page, I.H. The effect of renin, pitressin, and pitressin and atropine on renal blood flow and clearance. Am. J. Physiol. 126: 354 (1939).

2. De Wardener, H.E. \& Miles, B.E. The effect of haemorrhage on the circulatory autoregulation of the dog's kidney perfused in situ. Clin. Sci. 11:267 (1952).

3. Hatch, F.E. \& Johnson, J.G. Intrarenal blood flow. Ann. Rev. Med. 20: 395 (1969).

4. WaUgh, W.H. \& Shanks, R.G. Cause of genuine autoregulation of the renal circulation. Circ. Res. 8: 871 (1960).

5. SMrth, H.W. The kidney structure and function in health and disease. New York. Oxford University Press (1951).

6. Konner, P.I. Effects of low oxygen and of carbon monoxide on the renal circulation in unanaesthetized rabbits. Circ. Res. 12: 353 (1963).

7. Forster, R.P. \& MAEs, J.P. Effects of experimental neurogenic hypertension on renal blood flow and glomerular filtration rates in intact denervated kidneys of unanaesthetized rabbits with adrenal glands demedullated. Am. J. Physiol. 150: 534 (1947).

8. Miles, B.E. \& DE WArdener, H.E. Intrarenal pressure. J. Physiol. (Lond.) 123: 131 (1954).

9. ThUrau, K. Renal haemodynamics. Am. J. Med. 36: 698 (1964).

10. Grangsjo, G. \& Wolgast, M. The pressure flow relationship in renal cortical and medullary circulation. Acta. Physiol. Scand. 85: 228 ( 1972).

11. PAPpenheimer, J.R. and KINTER, W.B. Haematocrit ratio of blood within mammalian kidney and its significance for renal haemodynamics. Am. J. Physiol. 185: 377 (1956).

12. Hinshaw, L.B., Day, S.B., \& Carlson, C.H. Tissue pressure as a causal factor in the autoregulation of blood flow in the isolated perfused kidney. Am. J. Physiol. 197: 309 (1959).

13. Navar, L.G., Guyton, A.C., \& Langston, J.B. Effects of alteration in plasma osmolality on renal blood flow autoregulation. Am. J. Physiol. 211: 1387 (1964).

14. Semple, S.J.G. \& DE WARDENER, H.E. Effect of increased renal venous pressure on circulatory autoregulation of isolated dog kidneys. Circulation Res. 7: 643 (1959).

15. Thurav, K. \& Levine, D.Z. The renal circulation. The kidney, morphology, biochemistry, physiology. Vol. III. Rouiller, C. and Muller, A.F. Academic Press, New York and London (1971).

16. Leichtweiss, H.P. \& Schroder, H. Pflugers Archiv. Ges. Physiol. 293: 303 (1967).

17. Paddock, R.B., Parker, J.W., \& Guadagin, N.P. The effects of methoxyflurane on renal function. Anesthesiology 25: 707 (1964).

18. Crandall, W. B., Pappas, S.A., \& MacDonald, A. Nephrotoxicity associated with methoxyflurane anaesthesia. Anesthesiol. 27: 591 (1966).

19. Mazze, R.I., Shue, G.L., \& JACKson, S.H. Renal dysfunction associated with methoxyflurane anaesthesia. J.A.M.A. 216: 278 (1971).

20. Hollenberc, N.K., McDonald, F.D., Cotron, R., Galvanex, E., Worhol, M., Vandam, L., \& Merriml, J. Irreversible acute oliguric renal failure: a complication of methoxyflurane anaesthesia. N. Eng. J. Med. 286: 877 (1972).

21. Mazze, R.I., Trudell, J.R., \& Cousins, M.J. Methoxyflurane metabolism and renal dysfunction: clinical correlations in man. Anesthesiol. 35: 247 (1971).

22. Taves, D.R., Fry, B.S., Freeman, R.B., \& Gillies, A.J. Toxicity following methoxyflurane anaesthesia II. Fluoride concentrations in nephrotoxicity. J.A.M.A. 214: 91 (1970). 